Georgia State University

ScholarWorks @ Georgia State University

\title{
Academic Librarians, Professional Literature, and New Technologies: A Survey
}

Skye Hardesty

Georgia State University, skye@gsu.edu

Tammy Sugarman

Georgia State University, tsugarman@gsu.edu

Follow this and additional works at: https://scholarworks.gsu.edu/univ_lib_facpub

Part of the Library and Information Science Commons

\section{Recommended Citation}

Hardesty, Skye and Sugarman, Tammy, "Academic Librarians, Professional Literature, and New Technologies: A Survey" (2007). University Library Faculty Publications. 3.

https://scholarworks.gsu.edu/univ_lib_facpub/3

This Article is brought to you for free and open access by the Georgia State University Library at ScholarWorks @ Georgia State University. It has been accepted for inclusion in University Library Faculty Publications by an authorized administrator of ScholarWorks @ Georgia State University. For more information, please contact scholarworks@gsu.edu. 


\title{
Title
}

Academic Librarians, Professional Literature, and New Technologies: A Survey

\section{Authors}

Skye Hardesty

Science Librarian

Georgia State University Library

Atlanta, GA

$\underline{\text { skye@gsu.edu }}$

and

Tammy Sugarman

Head, Collection Development

Georgia State University Library

Atlanta GA

tsugarman@gsu.edu

\begin{abstract}
Keeping abreast of professional literature and the latest trends is critical for academic librarians to be successful, but in a time of information glut, are librarians achieving this? Over seven hundred academic librarians responded to this survey and inform us about their use of both traditional methods and new technologies to stay current.
\end{abstract}




\section{Introduction}

Keeping abreast of professional literature and the latest trends in librarianship and related fields is critical for academic librarians' success. However, with the increasing amount of information available twenty-four hours a day, the ability to keep current is more and more of a challenge. In addition to the quantity of information accessible to librarians, the advent of new technologies enables librarians to gather this information from more sources in faster ways. Moreover, the growth of the profession into areas such as classroom teaching, information systems and web technologies implies that librarians cannot limit themselves to gathering information and reading literature from strictly the "library" field. Instead, librarians must attempt to keep up with trends in education and information systems, for example, in addition to literature in disciplines in which they teach or collect materials.

\section{Purpose}

The authors' own experiences in combination with discussions with academic librarians at the authors' university led to the supposition that academic librarians feel it is important to stay current with professional literature and developments, but their ability to do so is limited by several factors. Faced with the challenges mentioned above, the authors were interested in whether academic librarians keep up successfully, and if so, how? Are academic librarians using technology to stay informed? If so, is it working? Do academic librarians feel overwhelmed by the challenge to constantly keep current, or do they believe they are adequately managing their professional information needs? The authors also wanted to know how new information management technologies are either helping or hindering librarians' ability to keep up. In the past two years, new technologies, such as RSS (Really Simple Syndication) feeds have been promoted as a way to easily collect and manage large amounts of information. ${ }^{1}$ The authors 
were curious about whether this technology is being used by librarians as widely as reported in the literature.

\section{Literature Review}

Information overload is a concept that has been discussed extensively over the past thirty years. ${ }^{2}$ Definitions of information overload vary, but some commonalities include the ideas that there is too much data produced for a person to evaluate effectively, there is too much unsolicited information received by people every day in every format, and there is an abundance of information that is not relevant or useful for one's particular purpose. Generally, it can be said that "information overload occurs when information received becomes a hindrance rather than a help when the information is potentially useful." ${ }^{3}$ Several studies have been done to ascertain the causes of information overload. In a 1996 Reuters Business Information study on information overload called "Dying for Information," over a thousand business managers in the United Kingdom, United States, Hong Kong and Singapore were interviewed. This study revealed several perceived causes of information overload: increases in communication methods such as fax, e-mail, teleconferencing and online conferencing, growth in the amount of information being communicated, and an expansion in the number of people within and outside of organizations that need to be included in the communication loop. ${ }^{4}$ Ali F. Farhoomand and Don H. Drury's empirical study asked over 100 business managers how they defined information overload. In descending order of frequency, managers cited "excessive volume of information," trouble managing the information, "irrelevance or unimportance" of most information found, "lack of time to understand it" and too many sources of information available. ${ }^{5}$ In her article on information overload and law librarians, Kathryn Hensiak suggests that members of the profession may be especially susceptible to information overload because as patrons expect 
librarians to be increasingly more knowledgeable; librarians feel pressured to master more functions and understand more subject areas, often simultaneously. This can result in librarians being exposed to so much information that they have a hard time putting a value on it. ${ }^{6}$ Other literature has focused on technology's role in the exacerbation of information overload. A recent article in The Chronicle of Higher Education found that scholars at academic institutions feel a "sense of information overload" when they have e-mail, blogs, and other communication technologies constantly coming at them in an "increasingly wired world."7

The negative effects of information overload can be stress, physical and mental illnesses such as headaches and depression, and non-productivity in life and work. In response to the question of how information overload affects their work, Farhoomand and Drury found that 72 percent of managers mentioned loss of time, 40 percent said information overload had a negative effect on work, 16 percent said it reduced efficiency, and 16 percent said information overload resulted in "frustration, tiredness and stress." 8 Forty-three percent of business managers interviewed in the United Kingdom for the Reuters study reported that they believe the "cost of collecting information exceeds its value to business." 9 In this same study, managers agreed that they needed a lot of information to do their jobs, but as one manager said, "[I] am often at a loss as to how to start dealing with it."10 Information overload in the library profession may be detrimental to patrons as well as librarians, according to Hensiak, because “...it seems that our reaction to information overload is to overload our patrons with more information than they need. More information does not necessarily result in our patrons being more knowledgeable.",11 In the last two years, several articles, as well as a book, have been written recommending tools and strategies for librarians to use to keep current with professional literature and developments in library and related fields. These articles are anecdotal in nature, based upon the 
opinion and observations of the authors. Most of these publications advise librarians to use technologies to minimize the amount of time required to stay abreast of trends and developments relevant to the profession. Steven Cohen's 2003 book provides librarians with practical Internet strategies to manage the deluge of information, including using technologies such as website monitoring software, RSS feeds, and blogs. Cohen's 2004 follow-up article consolidates these strategies into an "eight-step program" which includes step 2, choosing the method that works most effectively for one's own professional development currency, whether it be listservs, TOC services or RSS; step 3, being selective and finding content that best suits one's personal interests and professional development; and, step 5, "always being on the lookout for new resources."12,13 Roy Tennant recommends that librarians use both technology and human resources to keep up, including filtering, RSS feeds, knowledge of colleagues, and current awareness services. ${ }^{14,15}$ Steven Bell discusses various technologies to help professionals keep up including "push" technologies such as newsletters automatically delivered to an e-mail inbox, and "detect" technologies; that is, services that alert individuals to website changes such as the addition of new content. ${ }^{16}$ RSS feeds and blogs are a hybrid of push and detect technologies because they push content to the reader when new content is available. In addition to technology, Bell suggests developing a "keeping up" team within an organization to share the burden of monitoring and reading the extensive amount of information required to stay current. ${ }^{17}$ Wadham, MacLeod, Delumeau and Miller suggest that librarians use RSS feeds to reduce the amount of time required to find and organize professional literature, and their articles offer practical tips on how to find RSS feeds and subscribe to them. ${ }^{18}$ Dorothy Barr points out that librarians must now stay abreast of emerging technologies and methods of keeping up, just as much as keeping up with the information itself. ${ }^{19}$ 
A search of the literature did not reveal any studies that surveyed librarians to find out how they perceived the importance of keeping up, methods they used to keep up, and their overall sense of the difficulty or ease of staying current in today's information-rich landscape. The authors' survey attempted to address this gap in the literature.

\section{Methodology}

The authors sent a link to an anonymous web-based survey using the commercial survey product Zoomerang (http://www.zoomerang.com) as part of a message on February 14, 2005 to the following listservs: Information Literacy Instruction (ILI-L), University Libraries Section (ULS-L), Reference and User Services Association (RUSA-L), Acquisitions Librarians Electronic Network (ACQNET-L), Collection Development (COLLDV-L), and Web for Libraries (WEB4LIB). These listservs were selected in order to reach academic librarians in both public and technical services positions. The message and survey link were specifically addressed to academic librarians, and included an explanation about the scope and purpose of the survey along with contact information for the investigators. The investigators did not submit information about the survey to any weblogs, but the listserv message was subsequently posted by Rachel Singer Gordon on her blog, "Beyond the Job." The survey was accessible through midnight on March 15, 2005.

For clarification purposes, the survey included a statement that defined professional literature as library literature, subject specific literature for subject librarians, or any current awareness information that librarians read to keep up with issues, trends, etc. related to the librarian's job. The survey included a total of 14 questions about the tools and resources librarians use to keep up with professional literature and how librarians access professional literature and developments. The survey authors asked respondents to rank on a scale from 
"limits to a great extent" to "does not limit" those factors that affected a librarian's ability to keep up with professional literature and developments. The last question in the survey was open ended to allow respondents to provide any additional comments they wished to make about the topic. Approximately 20 percent of the respondents provided additional comments. The survey instrument is provided in Appendix A.

A total of 707 individuals completed the survey. Some questions allowed for more than one response, for example, survey takers could have chosen more than one method of keeping up in response to survey question 2. Some questions received fewer than 707 responses. For example, if a survey taker did not indicate "journal use" in survey question 2 as a method of keeping current, then the respondent would not have answered survey question 3, "On average, how often do you read journal/magazine articles?" Tables and graphs accompanying the discussion provide clarification on numbers and percentages of respondents.

\section{Survey Demographics}

The authors asked respondents to select their job position from the list provided, and also offered an option for respondents to list additional types of positions that were not included. As illustrated by Figure 1, the highest percentage (31 percent) of respondents identified themselves as working in reference/public services with 18 percent identifying their positions in the "other" category. Responses in the "other" category ranged from individual interpretations of the categories that were included, to a few groups not represented. The two largest groups not included in the original list of job positions were systems librarians and those librarians with both technical service and public service responsibilities. The authors asked this question in order to find out if there was a correlation between job position and the methods and reasons that librarians keep current. The authors aimed to survey both public and technical services librarians 
in order to obtain a broad picture of how academic librarians as a whole keep up, rather than how a specific category of librarian, such as reference or cataloging librarians, keep up. As illustrated in figure 1, the survey yielded a good representation of librarians with public and technical services job responsibilities. However, since the survey was not specifically targeted to these intended populations, the responses represent a self-selected sample based on voluntary inclusion. Librarians who were not interested in this topic may have chosen not to respond to the survey. It is important to keep in mind that the results of this survey inform the reader about the opinions of those librarians who chose to respond to the survey, and cannot be generalized to represent librarians' opinions as a whole.

\section{[Figure 1]}

\section{Librarians' Attitudes about Keeping Up}

Gauging the importance of current awareness to academic librarians in their professional lives informs the entire survey. Is keeping up perceived as an obligation of the job? Do academic librarians feel that staying on top of professional developments is integral to their work, or not? Asked, "Why do you feel the need to keep up with professional literature?" respondents could choose "for tenure and/or promotion requirements", "to stay current with developments in the profession”, "to get publication ideas", "I don't feel the need to keep up with professional literature on a regular basis", and "other, please specify". "To stay current with developments in the profession" was selected most often, with 97 percent of respondents indicating this as their reason for keeping up. Other highly rated selections include "to get publication ideas" (34 percent) and "for tenure and/or promotion requirements" (29 percent). In order to provide specificity in understanding how professional literature played a part in academic librarianship survey takers had the option to make additional comments and ninety- 
nine individuals chose to do so. The comments reflected several views but in general the respondents felt that keeping current was important in order "to do my job better and better serve my patrons." Others commented that they kept up to improve job performance on an ongoing basis and "to incorporate current trends" into their work, for example, enhancing library services at their institution.

Eleven individuals selected "I don't feel the need to keep up with professional literature." and the authors were curious as to why these librarians feel that they do not need to stay current. One issue frequently raised by the respondents in the additional comments portion of the survey was the quality of library professional literature and how it diminished the importance of keeping up. Two comments that reflected this opinion were, "Hate to say it, but I find most of the professional literature in academic librarianship to be dull and uninspired" and "Professional library literature is frequently of dubious value and quality." Another comment stressed that the literature itself was of little value, the respondent wrote, "because of this it almost always takes a low priority on my list of things to do." While the authors defined professional literature broadly so as to include professional reading outside of library science, these individuals preferred to focus on their perceptions of the inadequacy of library literature. Weighing the quality of one article over another, and separating out those articles that are worthwhile to one's professional development versus those that are not, certainly contributes to frustration in keeping up. However, the percentage of those individuals that indicated that they do not keep up was very small. This could mean that the perceived inferior quality of the literature was not a large enough inhibitor to make librarians avoid keeping up with professional literature, or it could mean that those librarians that do not keep up chose not take this survey.

[Figure 2] 


\section{Librarians' Methods for Keeping Up}

A primary focus of the survey was to find out what methods academic librarians use to keep up. Survey takers were asked, "How do you keep up with professional literature/stay current with professional developments? Choose all that apply." The methods offered in the survey were journal/magazine articles, blogs, RSS aggregators or XML readers, listservs, table of contents service or other e-mail alerts, professional conferences, virtual professional conferences (webcasts), and "other, please specify." The majority of respondents, 95 percent, chose listservs as their primary method of keeping up with professional literature. The large number of survey takers who chose this method was not surprising considering the call for participation in the survey was disseminated over listservs. When asked on average how often those who selected listservs read postings, 81 percent chose "daily". Most respondents, 45 percent, monitored fewer than 5 listservs and 37 percent subscribed to between five and nine. Only 121 survey takers monitored more than ten.

The popularity of listservs could also be attributed to a method of staying current that many of the survey takers mentioned was not included in the survey; that is, communication with colleagues. Of the ninety-four librarians that chose "other, please specify" in this question, forty five librarians mentioned the importance of talking with peers. Networking with colleagues was not included as an option specifically because the authors believed that type of interaction was covered by both listservs and conference attendance, but many respondents felt the need to explicitly state this as a distinct method for keeping current. "Need a question about learning from peers both at work (others in library or dept) or friends in the profession" and "What about talking with faculty or colleagues about recent developments and professional literature[?] This seems to be overlooked" were some of the comments written about the importance of keeping up 
by talking with peers. For many, talking over issues with colleagues was the best way to learn and discover what is going on in the profession. One individual noted, "I think networking with colleagues often brings out the best discussions of the latest topics/developments in library land."

The traditional method of reading journal and magazine articles was as popular a choice as listservs among survey takers; 94 percent of respondents chose this method. When asked how often they read journals, 34 percent of survey takers who chose this method read journal and magazine articles one to two times per week; 24 percent, two to three times per month; and, 21 percent, 3-4 times per week. Journal and magazine articles were predominately accessed though print (95 percent) and electronic personal or institutional subscriptions (75 percent), database queries (58 percent), and through free web sites (55 percent). Only seventy seven individuals indicated getting their journal and magazine articles through RSS feeds while 254 (38 percent) preferred table of contents or other e-mail alerts to electronically deliver journal and magazine information. On average, most librarians who took the survey scan or read five to nine journal/magazine publications on a regular basis. The popularity of journal and magazine articles as a method to keep up did not surprise the authors. Journal and magazine articles have been the primary venue for library science literature for much longer than the technology-assisted methods that respondents were queried about. Journals and magazines, both inside and outside the library field, are the most readily available source of information for academic librarians by nature of where they work. Not only are journals and magazines easy to access for an academic librarian but, as indicated by several comments, many libraries route journals and magazines among their staff, making it a simple way to get to this information with minimal effort. In addition, membership in a professional association frequently includes a subscription to the organization's professional publication. Clearly, with numbers of listservs and conference 
attendance as high and higher in popularity for the survey takers, journal and magazine articles were not the sole tool for keeping up that they once were. Certainly, currency and timeliness are problems with journals and magazines, as well as a lack of context that can be better served by discussions with colleagues.

Six hundred and two individuals chose professional conference attendance as a method of keeping up, making the combination of listservs, journal/magazine articles, and conference attendance the most popular_methods among the librarians who took the survey. Email alerts, such as saved searches or journal table of contents, and virtual conference attendance, i.e. webcasts, received 256 and 234 responses, respectively.

[Figure 3]

\section{Blogs/RSS Feeds}

In the keeping up literature of the last few years blogs and RSS aggregators/XML readers have been enthusiastically heralded as the technologies that will allow people to sift through large quantities of information with ease. The hope has been that these information collectors (aggregators) and alternative news sources will streamline the glut of information and provide the currency that traditional sources (i.e. journals) lack. Individuals choose what blogs to read and what news sources from which they want information delivered. Readers or aggregators allow people to put all this information in one place. RSS readers are accessible through the Web or downloaded to the desktop, thereby circumventing the clogged up e-mail inbox. Blogs and RSS are undoubtedly popular, and they are exciting technologies to use for keeping current on the wide variety of topics that are essential for academic librarians to be effective and knowledgeable. Since these new technologies are lauded as answers to managing information 
overload, why are so many academic librarians still having trouble keeping up? Are many librarians actually using blogs and RSS feeds to keep up? If they do, is it working?

Based on the survey results, blogs and RSS feeds were less popular than other methods to stay current. Only 28 percent (198 responses) of survey takers used blogs and only 15 percent (108 responses) used RSS aggregators or XML readers. Comments provided by survey takers offered reasons why those numbers are low. One individual wrote "Blogs are interesting, but I find that I receive more useful and relevant information through listservs" or, individuals felt as frustrated with RSS feeds as with other methods, "I just find myself overwhelmed with aggregator sites.... I find I read more by just reading the sources I already know about. I'm sure there's a lot I miss out on this way, but it's been the most successful for me thus far. And there are just too many blogs out there for me to invest the time to figure out which are worthy of making my 'regular read' list."

\section{[Table 1]}

Of those survey takers who monitored blogs, 82 percent monitored fewer than five, 10 percent more than ten, and 8 percent five to nine. There was a total of 645 responses to this question which was odd considering that only a total of 308 individuals chose blogs and RSS feeds as methods for keeping up (see figure 3). The authors assumed that a large number of the 527 individuals who chose "monitor less than 5 blogs" meant they did not monitor any blogs $(0)$. The authors based this assumption on the number of responses in the initial question about types of methods used to keep up (survey question 2) and on the 303 responses for "do not read blogs" in survey question 8, "If you read blogs, how long have you been using them?" Most of the individuals that read blogs indicated they have been using them for one year or more (24 
percent), with 12 percent reading blogs for six to eleven months, and 9 percent of respondents just starting (under two months). Another 9 percent have read blogs for two to five months.

When the authors asked the survey takers, "If you use RSS aggregators or XML readers, how long have you been using them," 459 of the 640 responses to the question were "do not use them.” The remaining 181 responses were divided up fairly equally among the remaining choices. Fifty two individuals have used RSS aggregators for six to nine months and forty eight for one year or more. Forty four respondents just started using them (less than two months) and the remaining thirty seven individuals have used them for two to five months. To follow up, the survey takers were asked how often those who read blogs and/or RSS feeds check them. There are a total of 639 responses to this question but only 174 respondents indicated they did not read blogs or use RSS feeds. The remaining choices, none of which is an option of "do not read blogs", garnered a total of 465 responses; however, only 306 individuals indicated they used blogs and RSS aggregators as methods for keeping up (see Figure 3). The authors do not have an explanation for why there are 159 additional responses to this particular question. For this particular question, the survey was set up to "jump" to the appropriate follow up question based on the answer the survey taker selected; perhaps the software failed to do so in this case. Another explanation might be that the question was written in way that did not make it clear to survey takers whether they were supposed to answer this question if they did not read blogs/use RSS aggregators. Regardless of the explanation, this error should be noted when looking at these results. Most of the survey takers (15 percent) read or checked their blogs and/or feeds daily, 14 percent checked one or two times a year, 10 percent one to three times per month, and 9 percent read three to four times per week. Survey takers that read blogs and XML readers on a monthly 
basis predominately checked two to three times per month (10 percent), with 8 percent checking every few months, and 6 percent reading once a month.

Opinions on the usefulness of blogs and RSS feeds/aggregators as information management tools for academic librarians appeared mixed. Some respondents had trepidations about blogs while others conveyed positive comments on the ease of collecting information and of the time saved with blogs and aggregators. One individual noted that, "Blogs and electronic access are two methods that have greatly increased my use of literature," while another wrote, “one of the reasons I read blogs to keep up is they don't require the time articles do and are more up to date." Most of the positive comments about blogs and RSS feeds dealt with their timeliness rather than their effectiveness as a management tool. Some librarians who did not use blogs responded they they just "never found the time for exploring these [blogs/RSS feeds]," or commented, "I would like to learn how to use RSS feeds and blogs." In general, the survey takers who did not use blogs/RSS feeds exhibited either ignorance about blogs, but openness to them ("I don't know what an RSS aggregator is"), or dismissal of this method as a valid keeping up tool ("I don't use blogs because I don't like the fact that they are often unmoderated,

unedited, and not peer reviewed"). One librarian succinctly voiced one of the problems blogs are perceived to have: "I think that traditional print resources have more prestige, but take more time of the reader. Techy [sic] resources, blogs and RSS feeds, take much less time, but are less prestigious."

\section{Librarians' opinions on successfully keeping up}

The previous questions in the survey were about why and how academic librarians keep up. In the final question of the survey, the authors asked how successfully librarians thought they kept up. The issues in this final (and required) question were time management in both 
collecting information and reading the collected information, time constraints in collecting professional literature at the workplace, or "on the job", and feelings of stress related to the sheer bulk of information applicable to staying current with our profession. Survey takers were asked explicitly, "Is your ability to keep up with professional literature and developments limited by the following?" The survey takers' choices were "not enough time to locate relevant information", "not enough time to read once information is found", "not enough time on the job to locate and/or read information", and "overwhelmed by the amount of information available" (see Table 2). The respondents had to indicate with each of the statements if it "limits to a great extent", "limits somewhat", or "does not limit". As shown in Table 2, most survey takers found that all statements "limit somewhat" their ability to keep up with professional literature and developments.

\section{[Table 2]}

It appeared that survey takers were not especially limited by time to locate relevant information (372 chose "limits somewhat" and 219 felt that not having enough time "does not limit"). The numbers indicated that most of the survey takers felt somewhat or greatly limited by the other three options, especially "not enough time to read once information is found" with 309 survey takers selecting "limits to a great extent" and 321 selecting "limits somewhat". "Not enough time on the job to locate and/or read information" received 336 responses for "limits somewhat" and 247 for "limits to a great extent", although 123 respondents felt they have enough time on the job to locate and read professional literature. "Overwhelmed by the amount of information available" is only limiting somewhat with 319 and 222 for "limits to a great extent", but 165 survey takers indicated they are not overwhelmed. 
Those individuals who chose to comment on how they keep up or the importance of keeping up voiced mostly frustration. "It always surprises me how difficult it is to find relevant information - I have not found a good way to keep current that I feel keeps me informed of the most important issues and developments in my area of expertise" one respondent wrote. More than a few librarians indicated that trying to stay current in the library field was an exercise in futility, with comments like, "I used to think that I kept up. Now I think I'll be happy just to recognize terminology, projects, new developments." Other librarians accepted that they would miss something despite their efforts to stay on top of professional developments, "I am generally able to keep up with what I need to know at a cursory level. I do not have the time to read in depth. This is OK..." One survey taker did see that, despite the difficulty in keeping up, there was something worthwhile in the pursuit itself, "There are lots of thing[s] out there. It is difficult to keep up but well worth it. I always find something interesting and worthwhile."

The authors, based on their hypotheses, expected academic librarians to be limited in having time to read professional literature, locating relevant information on the job, and being overwhelmed by the amount of information available. The respondents in this survey did support these hypotheses but were less limited in having time to locate information than in having enough time to read information once it was found. Respondents may be able to find time while on the job (for example, while working at the reference desk) to location information, but it is finding the time to read and digest the information that they perceive to be most limiting in their ability to keep up with professional literature and developments. The results of this question point to the fact that most academic librarians are limited by time or overwhelmed in the amount of information available to them, and therefore, limited in their ability to stay on top of new developments in library science and other areas key to their positions. 


\section{Conclusion}

It is encouraging to the authors that the librarians surveyed feel that it is important enough to their job performance and service to patrons and their libraries that they continue to keep abreast of developments in the library and related fields. The respondents did not indicate that they are so overwhelmed with finding and reading relevant information that they have entirely given up this pursuit. Instead, those surveyed indicated they are using multiple avenues for staying abreast of trends and advancements including more traditional methods such as talking with colleagues, attending conferences and reading journal articles, as well as newer technologies such as blogs and RSS feeds. However, despite the emphasis in the current literature about the need to use blogs and RSS feeds to keep up, these methods were least popular with the survey takers at the time of the survey. Since the survey was done, usage of these methods may have increased, but because there are numerous aggregators available for RSS feeds, and it is not necessary to subscribe to a blog in order to read it, it is difficult to assess these numbers in any meaningful way. For example, the ACRLog receives approximately 2,500 visits per day and has approximately 400 people who subscribe to the blog using Bloglines. ${ }^{20}$ When these numbers are compared to the ACRL approximate membership of 12,000 people, it appears that usage is quite limited. This is an area for further research as blogs and RSS feeds become more "mainstream" and readers have greater experience using them as a method to keep up with professional literature and developments. Future studies could examine whether or not librarians perceive blogs and RSS feeds to be time saving mechanisms for staying current, or if they are seen as another just technology that adds to the information glut. 


\section{Figure 1}

Areas of respondents' primary job responsibilities

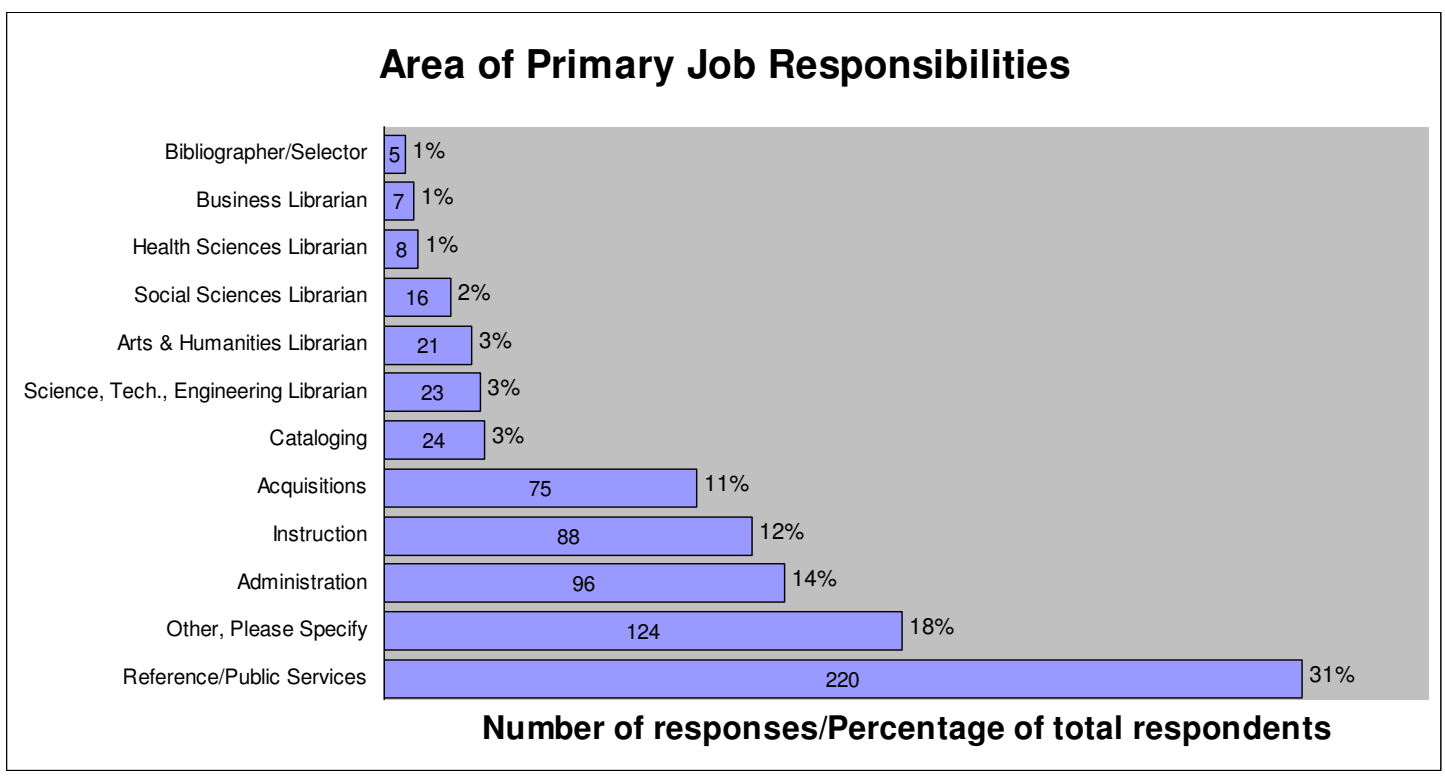

Note: All respondents (707) answered this question 
Figure 2

Reasons librarians keep up with professional literature (Survey Question 12)

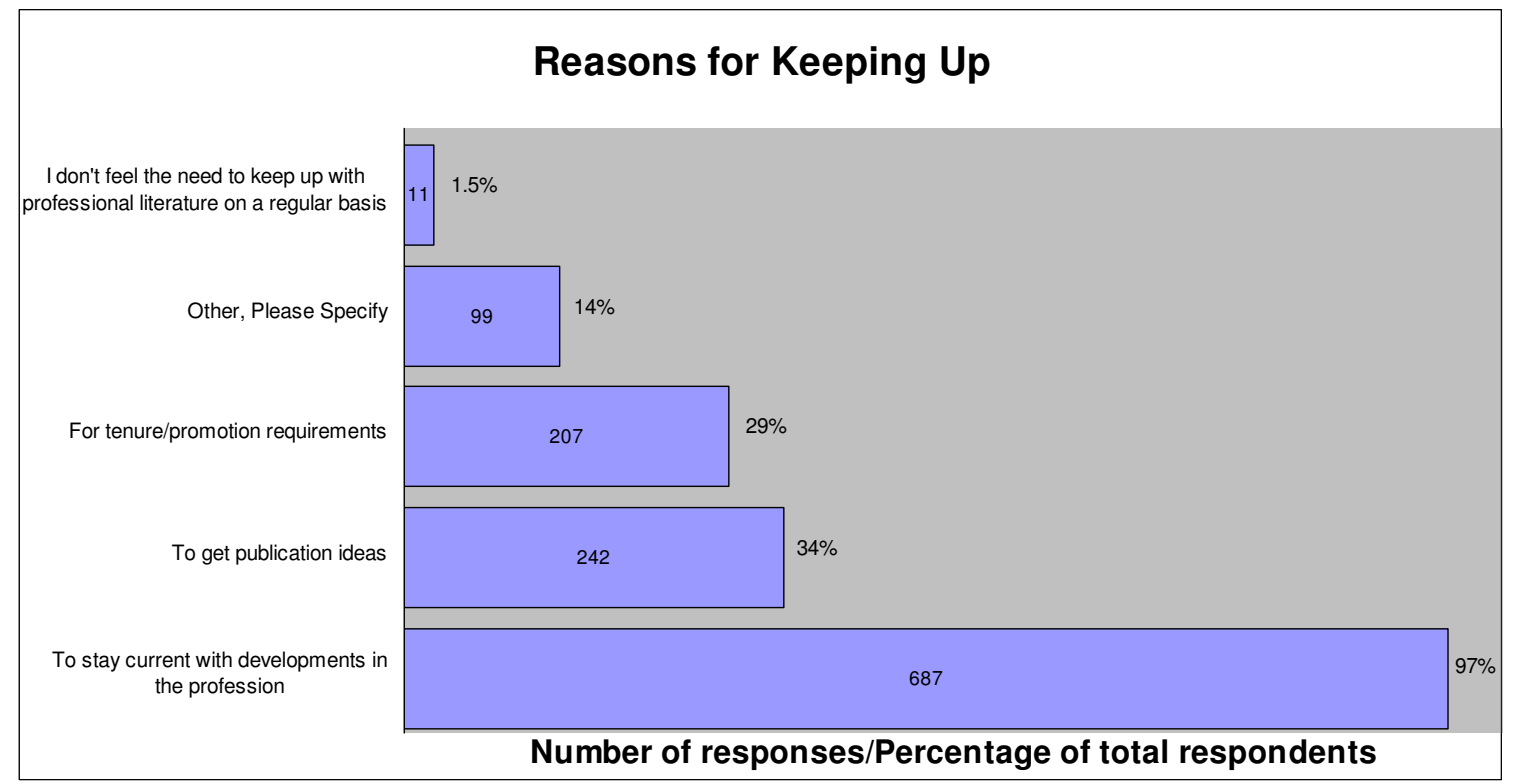

Note: All respondents (707) answered this question. Respondents could choose more than one answer. 
Figure 3

Ways respondents keep up with professional literature /

stay current with professional developments (Survey Question 2)

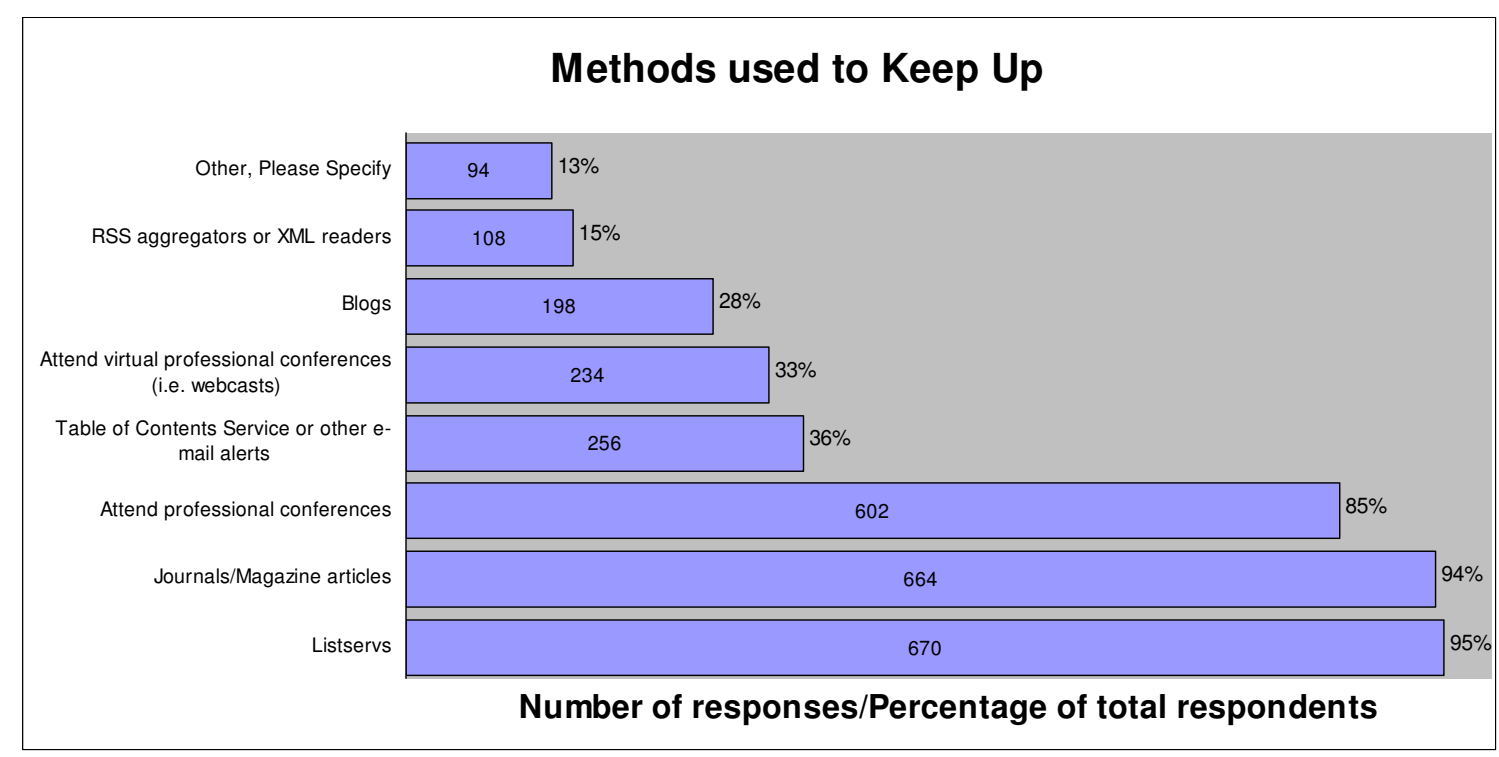

Note: All respondents (707) answered this question. Respondents could choose more than one answer.

Formatted: Justified, Line spacing: 
Table 1

Respondents' use of blogs/RSS Aggregators/XML Readers

If you read blogs, how long have you been using them? (Survey Question 8)

Note: 648 respondents answered this question

\begin{tabular}{|l|l|l|}
\hline \multicolumn{2}{|c|}{ Number of Responses } & Response ratio \\
\hline $\begin{array}{l}\text { Just started } \\
\text { (less than 2 months) }\end{array}$ & 59 & 9 percent \\
\hline $2-5$ months & 56 & 9 percent \\
\hline $6-11$ months & 75 & 12 percent \\
\hline 1 year or more & 155 & 24 percent \\
\hline Do not read blogs & 303 & 47 percent \\
\hline
\end{tabular}

If you use RSS Aggregators or XML Readers, how long have you been using them?

(Survey Question 9)

Note: 640 respondents answered this question

\begin{tabular}{|l|l|l|}
\hline \multicolumn{2}{|c|}{ Number of Responses } & Response Ratio \\
\hline $\begin{array}{l}\text { Just started } \\
\text { (less than 2 months) }\end{array}$ & 44 & 7 percent \\
\hline $2-5$ months & 37 & 6 percent \\
\hline $6-9$ months & 52 & 8 percent \\
\hline 1 year or more & 48 & 8 percent \\
\hline Do not use them & 459 & 72 percent \\
\hline
\end{tabular}


Table 2

Factors that limit librarians' ability to keep up (Survey Question 13)

Is your ability to keep up with professional literature and developments limited by the following?

Note: The percentage indicates the response ratio; the number represents actual number of respondents selecting the option.

\begin{tabular}{|l|c|c|c|}
\hline & 1 & 2 & 3 \\
& Limits to a great extent & Limits somewhat & Does not limit \\
\hline $\begin{array}{l}\text { Not enough time to locate } \\
\text { relevant information }\end{array}$ & 16 percent & 53 percent & 31 percent \\
\hline $\begin{array}{l}\text { Not enough time to read once } \\
\text { information is found }\end{array}$ & 44 percent & 45 percent & 11 percent \\
\hline Not enough time on the job to & 309 & 321 & 76 \\
locate and/or read information & 35 percent & 48 percent & 17 percent \\
\hline Overwhelmed by the amount & 247 & 336 & 123 \\
of information available & 31 percent & 45 percent & 23 percent \\
\hline
\end{tabular}

Note: All respondents (707) answered this question 


\section{Appendix A: Survey Instrument}

\section{"Professional Literature Survey for Academic Librarians"}

For the following questions, we are defining professional literature as library literature, subject specific literature for subject librarians, or any current awareness information that librarians read to keep up with issues, trends, etc. related to their jobs.

1. Please indicate the area of your primary job responsibilities as an academic librarian.

- Reference/Public Services

- Instruction

- Cataloging

- Acquisitions

- Bibliographer/Selector

- Subject Librarian or Liaison - Arts \& Humanities

- Subject Librarian or Liaison - Social Sciences

- Subject Librarian or Liaison - Health Sciences

- Subject Librarian or Liaison - Science, Technology, Engineering

- Subject Librarian or Liaison - Business

- Administration

- Other, Please Specify

2. How do you keep up with professional literature/stay current with professional developments? Choose all that apply.

- Journal/Magazine articles

- Blogs

- RSS aggregators or XML readers

- Listservs

- Table of Contents Service or other e-mail alerts

- Attend professional conferences

- Attend virtual professional conferences (i.e. webcasts)

- Other, Please Specify

3. On average, how often do you read journal/magazine articles?

- Daily

- 3 - 4 times per week

- 1 - 2 times per week

- 2 - 3 times per month

- Once a month

- Every few months

- 1 - 2 times per year

- Other, Please Specify 
4. How do you access journal/magazine articles? Choose all that apply.

- Through personal or institutional print subscriptions

- Through personal or institutional electronic subscriptions

- Through free web sites

- Through database queries

- Through table of contents or other e-mail alerts

- Through RSS feeds

- Other, Please Specify

5. On average, how many journal/magazine publications do you scan or read on a regular basis?

- More than 10

- 5 - 9

- Less than 5

6. On average, how many blogs or feeds do you monitor/subscribe to?

- More than 10

- 5 - 9

- Less than 5

7. On average, how often do you check/read Blogs and/or RSS aggregators or XML readers?

- Daily

- 3 - 4 times per week

- 1 - 2 times per week

- 2 - 3 times per month

- Once a month

- Every few months

- 1 - 2 times per year

- Other, Please Specify

8. If you read BLOGS, how long have you been using them?

- 1 year or more

- 6 - 11 months

- 2 - 5 months

- Just started (less than 2 months)

- Do not read Blogs

9. If you use RSS Aggregators or XML Readers, how long have you been using them?

- 1 year or more

- 6 - 9 months

- 2 - 5 months

- Just started (less than 2 months)

- Do not use them 
10. On average, how many listservs do you monitor/subscribe to?

- More than 10

- 5 - 9

- Less than 5

11. On average, how often do you read listserv postings?

- Daily

- 3 - 4 times per week

- 1 - 2 times per week

- 2 - 3 times per month

- Once a month

- Every few months

- 1 - 2 times per year

- Other, Please Specify

12. Why do you feel the need to keep up with professional literature? Choose all that apply.

- For tenure and/or promotion requirements

- To stay current with developments in the profession

- To get publication ideas

- I don't feel the need to keep up with professional literature on a regular basis

- Other, Please Specify

13. Is your ability to keep up with professional literature and developments limited by the following?

- Not enough time to locate relevant information

- Not enough time to read once information is found

- Not enough time on the job to locate and/or read information

- Overwhelmed by the amount of information available

- (for each option survey takers chose one of the following: "Limits to a great extent", "Limits somewhat", or "Does not limit")

14. Please provide any additional comments you wish to make about the topic of how academic librarians keep up with professional literature/developments. 
References

1. Ron Miller, "Can RSS Relieve Information Overload?" EContent 27 (March 2004): 20-24.

2. David Allen and T.D. Wilson, "Information Overload: Context and Causes," The New Review of Information Behaviour Research 4 (2003): 31-44.

3. David Bawden, Clive Holtham, and Nigel Courtney, "Perspectives on Information Overload," Aslib Proceedings 51 (September 1999): 249-55.

4. "Dying for Information?" (New York: Reuters Business Information, 1996).

5. Ali F. Farhoomand and Don H. Drury, "Managerial Information Overload," Association for Computing Machinery. Communications of the ACM 45 (October 2002): 127-31.

6. Kathryn Hensiak, "Too Much of a Good Thing: Information Overload and Law Librarians," Legal Reference Services Quarterly 22, no. 2/3 (2003): 85-98.

7. Jeffrey R. Young, "Knowing When to Log Off," Chronicle of Higher Education April 22, 2005, A34.

8. Farhoomand and Drury, "Managerial Information Overload," 128.

9. "Dying for Information?" 17.

10. Ibid.

11. Hensiak, "Too Much of a Good Thing: Information Overload and Law Librarians," 93.

12. Steven M. Cohen, Keeping Current: Advanced Internet Strategies to Meet Librarian and Patron Needs (Chicago: American Library Association, 2003).

13. Steven M. Cohen, "Eight Steps for Keeping Current," Knowledge Quest 33 (September/October 2004): 40-41.

14. Roy Tennant, "Strategies for Keeping Current," Library Journal, September 15 2003, 28. 
15. Roy Tennant, "Feed Your Head: Keeping up by Using RSS," Library Journal, May 15 2003, 30.

16. Steven J. Bell, "To Keep up, Go Beyond," College \& Research Libraries News 61 (July/August 2000): 581-84.

17. Steven J. Bell, "Keeping Up: Using E-Resources for a Personalized PD Program," Educause Quarterly 26, no. 3 (2003): 53-55.

18. Andrea Delumeau, Keeping up with RSS. Online. LIScareer.com (October 23, 2004), Available: http://www.LIScareer.com (accessed July 12, 2005); Roddy MacLeod, RSS: Less Hype, More Action. Online. FreePint (June 17, 2004), available from http://www.freepint.com/issues/170604.htm (accessed May 31, 2005); Ron Miller, "Can RSS Relieve Information Overload?"; Rachel Wadham, "Rich Site Summary (RSS)," Library Mosaics 16 (January/February 2005): 25.

19. Dorothy Barr, "Staying Alert: The Wild New World of Current Awareness Services," $C \& R L$ News 67 (January 2006): 14-17.

20. Steven Bell, e-mail message to Skye Hardesty, March 9, 2006. 